\section{Single-balloon endoscopy to remove a migrated esophageal stent in the small bowel}



Fig. 1 Abdominal radiograph demonstrated an impacted metal foreign body in the left lower portion of the abdomen in a 49-year-old woman. There were no signs of pneumoperitoneum.

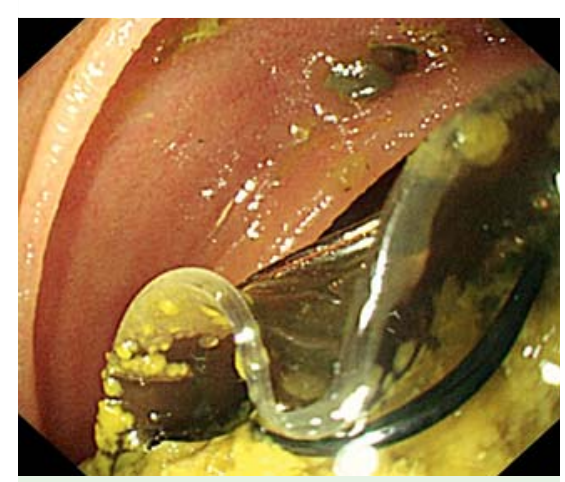

Fig. 2 The stent was found approximately $150 \mathrm{~cm}$ from the pylorus.

A 49-year-old woman was admitted to the hospital emergency department having had abdominal pain for 16 hours. She had previously undergone placement of a fully covered anti-reflux metal stent to treat esophageal achalasia (achalasia of cardia). On physical examination, the abdomen was soft with normal bowel sounds. However, there was tenderness on deep palpation of the left lower abdomen. All laboratory test results were within reference ranges. An abdominal radiograph demonstrated an impacted metal foreign body in the left lower portion of the abdomen without signs of pneumoperitoneum ( Fig. 1). Single-balloon endoscopy was performed (Olympus SIF-Q260; Olympus, Inc., Tokyo, Japan). At approximately 150

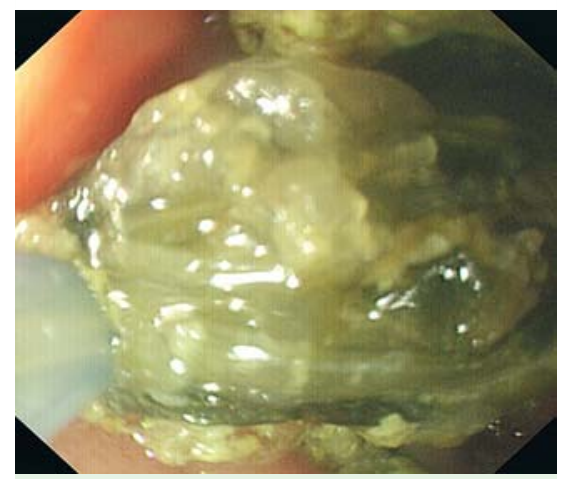

Fig. 3 The stent was grasped with a snare.

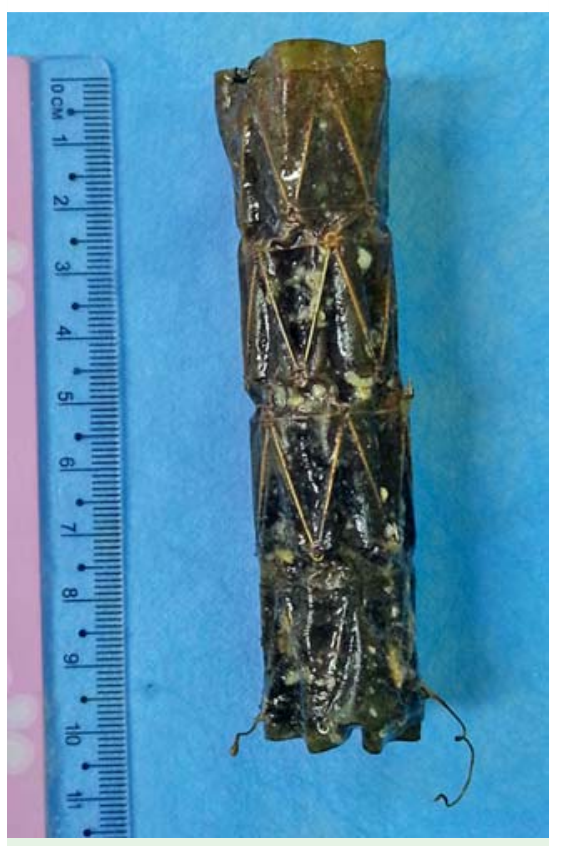

Fig. 4 Retrieved stent.

$\mathrm{cm}$ from the pylorus, the stent was found ( $\bullet$ Fig. 2). It was grasped with a snare and extracted ( $\bullet$ Fig.3, $\bullet$ Fig.4). An abdominal radiograph that was performed after the end of the procedure did not reveal pneumoperitoneum. The patient was discharged the following day.

Most ingested foreign bodies will be asymptomatic and pass through the gastrointestinal tract without complication or medical intervention [1-3]. Certain foreign bodies, however, such as sharp, pointed, or corrosive objects, have been typically associated with perforation. The initial diagnosis of foreign body ingestion may be difficult in the absence of a witness, and the presentation of perforation in such a case may be difficult to distin- guish from other causes of acute abdomen. The management of asymptomatic foreign bodies is variable and has been generally dictated by the site, type of foreign body, and anticipated likelihood of complications. If symptoms occur or there is concern regarding potential complications then removal is undertaken. Options for removal include endoscopy and surgery [4]. Laparoscopy has an important emerging role in both the diagnosis and the surgical management of ingested foreign bodies [5].

\section{Endoscopy_UCTN_Code_CPL_1AH_2AD}

\section{Competing interests: None}

\section{Na Li, Xiao-jun Zhao, Hai-hong Wang, Xin Wang, Jian-qiu Sheng}

Department of Gastroenterology, The Military General Hospital of Beijing PLA, Beijing 100700, P. R. China

\section{References}

1 Antao B, Foxall G, Gusik I et al. Foreign body ingestion causing gastric and diaphragmatic perforation in a child. Pediatr Surg Int 2005; 21: $326-328$

2 Arana A, Hauser B, Hachimi-Idrissi S et al. Management of ingested foreign bodies in childhood and review of the literature. Eur J Pediatr 2001; 160: 468-472

3 Lin M-T, Yeung C-Y, Lee H-C et al. Management of foreign body ingestion in children: experience with 42 cases. Acta Paediatr Taiwan 2003; 44: 269-273

$4 \mathrm{Kim}$ JK, Kim SS, Kim JI et al. Management of foreign bodies in the gastrointestinal tract: an analysis of 104 cases in children. Endoscopy 1999; 31: $302-304$

5 Law WL, Lo CY. Fishbone perforation of the small bowel. Laparoscopic diagnosis and laparoscopically assisted management. Surg Laparosc Endosc Percutan Tech 2003; 13: $392-393$

\section{Bibliography}

DOI http://dx.doi.org/

10.1055/s-0034-1365438

Endoscopy 2014; 46: E268

(c) Georg Thieme Verlag KG

Stuttgart · New York

ISSN 0013-726X

\section{Corresponding author \\ Jian-qiu Sheng, MD}

Department of Gastroenterology

The Military General Hospital of Beijing PLA

Nanmencang 5\#

Dongcheng District

Beijing 100700

P. R. China

Fax: +86-10-66721299

jianqiu@263.net 